Published in "Electrochimica Acta 134: 215-221, 2014"

which should be cited to refer to this work.

\title{
Impact of composite structure and morphology on electronic and ionic conductivity of carbon contained $\mathrm{LiCoO}_{2}$ cathode
}

\author{
Nam Hee Kwon ${ }^{\mathrm{a}, *}$, Hui Yin ${ }^{\mathrm{a}}$, Pierre Brodard ${ }^{\mathrm{b}}$, Claudia Sugnaux ${ }^{\mathrm{a}}$, Katharina M. Fromm ${ }^{\mathrm{a}}$ \\ a University of Fribourg, Department of Chemistry, Chemin du Musée 9, CH-1700 Fribourg, Switzerland \\ ${ }^{\mathrm{b}}$ University of Applied Sciences of Western Switzerland, College of Engineering and Architecture of Fribourg, Boulevard de Pérolles 80, CH-1705 Fribourg, \\ Switzerland
}

\begin{abstract}
Cathodes in lithium ion batteries consist of an ionic conductor, an electronic conductor and a binder in order to make a composite that is both electronically and ionically conductive. The carbon coating on the cathode material plays a critical role for the electrochemical properties of lithium ion batteries due to the increased electronic conductivity. We explain the relationship between the electrochemical properties and the characteristics of composites prepared using the ball-milling process in this report. We investigated two types of carbonaceous materials (graphite and carbon black) in $\mathrm{LiCoO}_{2}$ electrodes. These selected carbon materials have different characteristics and structure upon ball-milling with $\mathrm{LiCOO}_{2}$. The composite prepared by ball-milling for 5 min leads to better mixing of carbon and $\mathrm{LiCoO}_{2}$, an intimate contact of carbon on $\mathrm{LiCoO}_{2}$, a higher lithium ion diffusion $\left(\mathrm{D}_{\mathrm{Li}}\right)$ than non ball-milled and longer ball-milled composites. On the other hand, a longer time of ball-milling (30 and $60 \mathrm{~min}$ ) decreases the electronic and ionic conductivity due to an increase of disordered structure of carbon and a thick and dense carbon coating layer on $\mathrm{LiCoO}_{2}$ particles, preventing the diffusion of lithium ions, respectively.
\end{abstract}

\section{Introduction}

High-performance cathodes of lithium ion batteries require to be electronically and ionically conductive in order to facilitate the fast transport of electrons and lithium ions that are inserted or extracted from the transition metal oxide particles $\left(\mathrm{LiCoO}_{2}\right.$, [1-5] $\mathrm{LiMn}_{2} \mathrm{O}_{4}$, [6] $\mathrm{LiMO}_{2}$ (M=mixed transition metals), [7,8] $\mathrm{LiFePO}_{4}$, $\mathrm{LiMnPO}_{4}[9,10]$ etc.). In general, the ionic conductors of cathode materials need an electronic conductor to improve the electronic conductivity of the electrode. Carbon material is commonly used as a conductive additive to facilitate the transport of electrons in the cathode. The electronic conductivity of carbon depends on its purity, its ordered and/or disordered structure, the manufacturing processes and the carbonaceous sources etc. [11-13].

More importantly, the electronic conductivity of composite is not only related to the carbon material itself but also the process of assembling the composite together with the active material, which strongly influences the composite structure [14-18]. Therefore, the preparation of composite is a crucial step to maximize the

\footnotetext{
* Corresponding author.Tel.: +41 7967800 08; fax: +41 263009738 . E-mail addresses: namhee.kwon@unifr.ch, nhkwon2011@hotmail.com (N.H. Kwon).
}

electrochemical properties of the electrode. Recently, Kwon reported that the morphology of composite is affected by the preparation conditions of making a composite via ball-milling [18]. A mechanical mixing improves the homogeneity of carbon and the active material, enhancing the electrochemical properties of cathode. However, there are still scientific questions about a ballmilling process remaining as follows; i) does the ball-milling affect the local structure of carbon? ii) does the electronic conductivity of the composite change upon ball-milling?, and iii) knowing that mechanical milling breaks large particles, how would the lithium ion diffusion of the active material be affected upon milling? To answer those questions, we evaluated the effect of ball-milling in terms of the electronic and ionic conductivity of composite as well as the structure of carbon and the morphology of composite prepared by ball-milling.

\section{Experimental}

Graphite (SFG, Timcal, Belgium) and carbon black (Ketjenblack 600, Akzo Nobel, Germany) were used to prepare a composite material with commercial $\mathrm{LiCoO}_{2}$ (Aldrich). These carbon materials are referred to as "SFG" and "Ket", respectively, in the following. These materials were ball-milled in a horizontal set-up (Retch MM 400 ) for 5,30 or $60 \mathrm{~min}$ with $30 / \mathrm{s}$ of the frequency in a jar of 

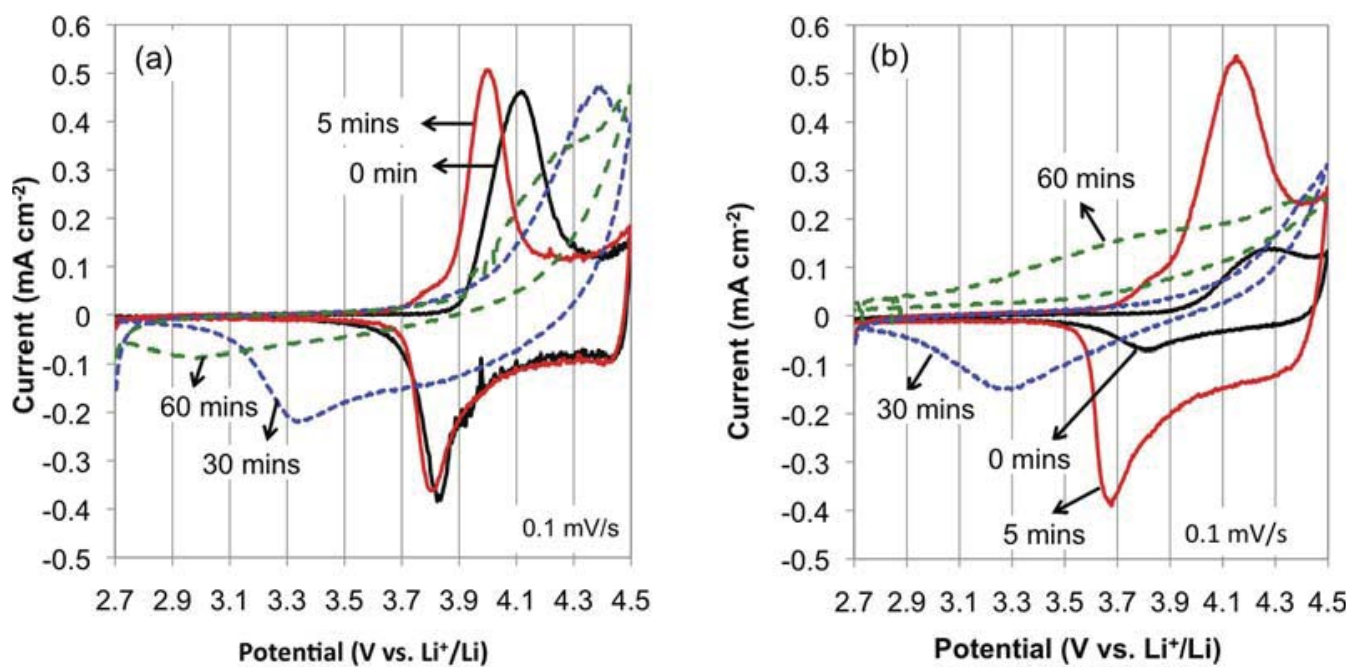

Fig. 1. The cyclic voltammograms of carbon/LiCoO 2 composite electrodes (a) with $10 \mathrm{wt} \%$ of SFG and (b) with 10 wt\% of Ket prepared by ball-milling for 0,5 , 30 and 60 min. The sweep scan rate was $0.1 \mathrm{mV} / \mathrm{s}$. The electrolyte was EC:DMC with $1 \mathrm{M} \mathrm{LiPF}_{6}$ salt.

$10 \mathrm{ml}$ with two stainless steel balls of $10 \mathrm{~mm}$ in diameter. After creating a composite of carbon and $\mathrm{LiCoO}_{2}$ via ball-milling, an electrode was prepared on aluminum foil with the composite of carbon/ $\mathrm{LiCoO}_{2}\left(\mathrm{C}-\mathrm{LiCoO}_{2}\right)$ and polyvinylidene fluoride (PVDF) in $\mathrm{N}$ methyl-2-pyrrolidone (NMP). The weight ratio of the $\mathrm{LiCoO}_{2}$ active material, carbon and binder was 80:10:10. The tested cathodes had $5 \times 5 \mathrm{~mm}$ of surface area and contained typically about $1 \mathrm{mg}$ of active material after drying. The electrodes were dried under vacuum at $120^{\circ} \mathrm{C}$ overnight. Lithium metal and ethylene carbonate (EC) and dimethyl carbonate (DMC) mixture $(1: 1 \mathrm{v} / \mathrm{v})$ with $1 \mathrm{M}$ $\mathrm{LiPF}_{6}$ were used as a counter electrode and electrolyte, respectively. A potentiostat (Princeton Applied Research 273A) and an Arbin battery test instrument (version 4.27) were used to examine the electrochemical properties of the carbon- $\mathrm{LiCoO}_{2}$ composite electrodes.

Raman spectroscopy was applied to study the structure of carbon before and after ball-milling. The experiments were carried out with a confocal micro-Raman spectrometer (HORIBA LabRAM HR800, combined with an optical microscope Olympus BX41). We used a laser at $531.8 \mathrm{~nm}$ for excitation, attenuated with neutral density filters (ND0.4 and ND2, 60\% and 99\% attenuation, respectively), resulting in laser powers of $16 \mathrm{~mW}$ and $0.4 \mathrm{~mW}$ on sample with the $50 \mathrm{X}$ objective employed, respectively. Because of the concentration of the light onto a very small spot (diameter approx. $2 \mu \mathrm{m}$ ), the attenuation of the laser power with filters was necessary to avoid thermal degradation of the sample. The acquisition time was set to $2 \times 0.5 \mathrm{~s}$. The morphology and the size of the particles were determined using scanning electron microscopy (SEM, Philips XL30) and

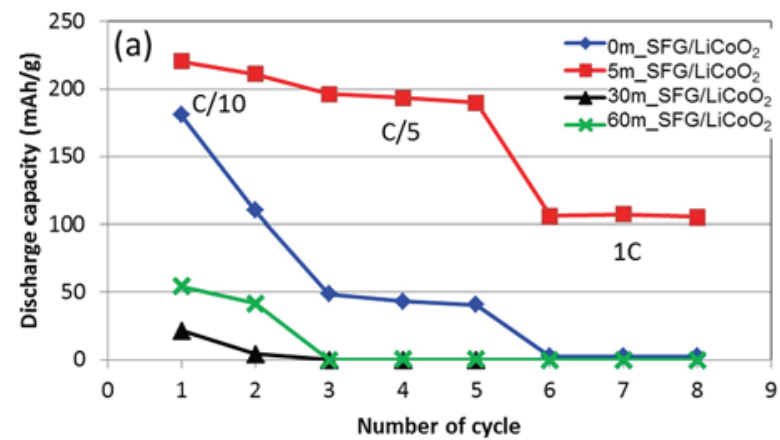

transmission electron microscopy (TEM, FEI/Philips CM 100). The Brunauer-Emmett-Teller (BET) nitrogen adsorption method was used to measure the specific surface area of $\mathrm{LiCoO}_{2}$, carbon materials and $\mathrm{C}-\mathrm{LiCoO}_{2}$ composites before and after ball-milling. The electronic conductivity was measured with dense pellets of composites and $\mathrm{LiCoO}_{2}$ material using direct current (DC) with the 4-point probe method. The pellets in $13 \mathrm{~mm}$ of diameter were pressed by 5 tons in order to make a dense body. The lithium ion diffusion coefficients $\left(D_{\mathrm{Li}}\right)$ of the electrodes were determined by cyclic voltammetry technique using the linear relationship between peak current, the linear sweep rate and ion diffusion constant from the Randles-Sevcik equation [19]. Each ion diffusion coefficient is the mean value of three electrodes tested under the same measurement conditions.

\section{Results and discussion}

The different electrode composite materials with SFG and Ket were investigated for their electrochemical properties. Fig. 1 shows the cyclic voltammogram curves of SFG and Ket containing $\mathrm{LiCoO}_{2}$ composite electrodes. The composite of $\mathrm{SFG} / \mathrm{LiCoO}_{2}$ prepared by ball-milling for 0 and $5 \mathrm{~min}$ showed sharp redox current peaks, while the 30 and $60 \mathrm{~min}$ of ball-milled composites had a wider potential distance between the reduction and oxidation current peaks and broader peaks at both redox events (Fig. 1(a)). With the Ket/LiCoO ${ }_{2}$ composite (Fig. 1 (b)), the redox current densities without ball milling are weaker, and for 30 and 60 min even irreversible, while only the $5 \mathrm{~min}$ ball-milled sample shows good reversible

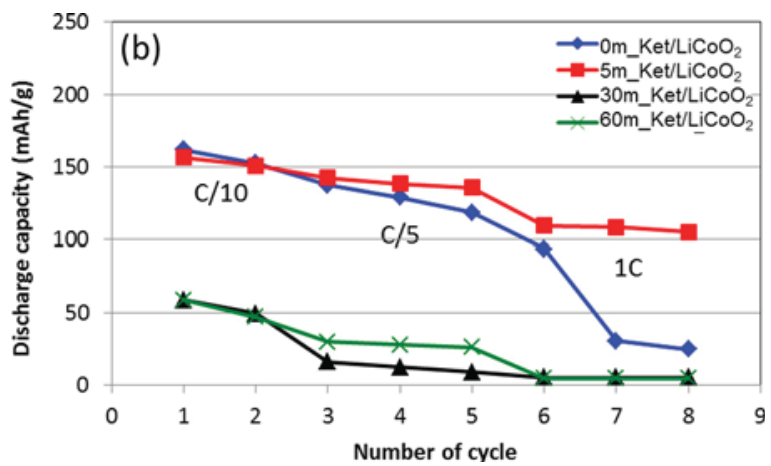

Fig. 2. The rate capacities (C/10, C/5 and $1 \mathrm{C}$ ) of the composites electrodes $\mathrm{SFG} / \mathrm{LiCoO}_{2}$ (a) and $\mathrm{Ket} / \mathrm{LiCoO}_{2}$ (b). The composites were prepared by ball-milling for $0,5,30$ and $60 \mathrm{~min}$. The voltage window was between 2.7 and $4.4 \mathrm{~V} v$ s. $\mathrm{Li}^{+} / \mathrm{Li}$. Li metal and EC:DMC with $1 \mathrm{M} \mathrm{LiPF}_{6}$ were used as anode and electrolyte, respectively. 

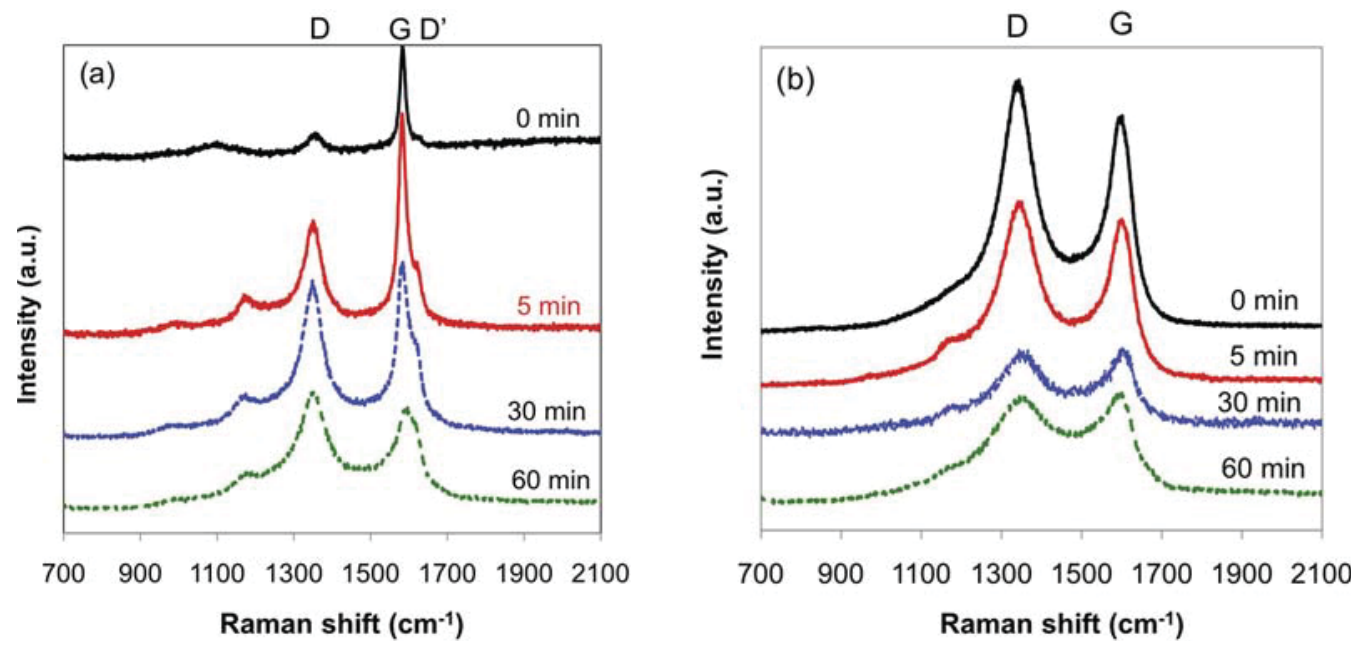

Fig. 3. Raman spectrum of (a) $\mathrm{SFG} / \mathrm{LiCoO}_{2}$ and (b) $\mathrm{Ket} / \mathrm{LiCoO}_{2}$ composite prepared by ball-milling for various time.

redox behavior. Thus, a short ball-milling provided superior electrochemical properties compared to no or longer ball-milling.

Fig. 2 (a) and (b) show the discharge capacities of the composites, SFG/LiCoO 2 and $\mathrm{Ket} / \mathrm{LiCoO}_{2}$ at $\mathrm{C} / 10, \mathrm{C} / 5$ and $1 \mathrm{C}$. The voltage window was between 2.7 and $4.4 \mathrm{~V}$ vs. $\mathrm{Li}^{+} / \mathrm{Li} .5 \mathrm{~min}$ ball-milled $\mathrm{SFG} / \mathrm{LiCoO}_{2}$ composite electrode provided the highest discharge capacities of 220, 196 and $106 \mathrm{mAh} / \mathrm{g}$ at C/10, C/5 and $1 \mathrm{C}$, respectively, among all different ball-milling processes shown in Fig. 2 (a). The first capacity of non-ball-milled $\mathrm{LiCoO}_{2}$ composite electrode reached over $150 \mathrm{mAh} / \mathrm{g}$ at $\mathrm{C} / 10$, which is the maximum practical capacity. However, the following capacities decreased rapidly probably due to the high upper voltage limit $\left(4.4 \mathrm{~V}\right.$ vs. Li/ $\left.\mathrm{Li}^{+}\right)$. Fig. 2(b) shows the same trend of the ball-milling effect, since the $5 \mathrm{~min}$ ball-milled $\mathrm{Ket} / \mathrm{LiCoO}_{2}$ composite electrode reached the highest discharge capacities of 156,142 and $109 \mathrm{mAh} / \mathrm{g}$ at C/10, C/5 and $1 \mathrm{C}$, respectively among the series of $\mathrm{Ket} / \mathrm{LiCoO}_{2}$ composite electrodes. The discharge capacities of 5 min ball-milled SFG/LiCoO ${ }_{2}$ composite electrode are higher than those of $5 \mathrm{~min}$ ball-milled $\mathrm{Ket} / \mathrm{LiCoO}_{2}$ at all studied current densities.

In order to evaluate the effect of a short and long time of ball-milling on the electrochemical properties, the C-C bond structures of both carbon materials were first characterized by Raman spectroscopy. Fig. 3 (a) SFG and (b) Ket show two main bands at 1350 and $1580 \mathrm{~cm}^{-1}$, corresponding to disordered D and ordered G band, respectively [20]. In case of Fig. 3 (a), the ratio of intensities $\mathrm{I}_{1350} / \mathrm{I}_{1580}$ increases upon the milling time. It means that the disordered $\mathrm{D}$ band becomes more dominant in the structure of SFG upon milling. Fig. 3 (b) shows the Raman spectrum of Ket in the composite, indicating not surprisingly that the initial Ket leads to a higher intensity of disordered $D$ band at $1350 \mathrm{~cm}^{-1}$ than the one for the $G$ band at $1580 \mathrm{~cm}^{-1}$. Both $D$ and $G$ bands at 1350 and $1580 \mathrm{~cm}^{-1}$ get broader and lower in intensities upon ball-milling. The ball-milling process increases thus the density of defects and/or reduces the crystallite size [21]. In addition, the band at $1200 \mathrm{~cm}^{-1}$ in ballmilled SFG and Ket is indicative of the presence of amorphous $\mathrm{sp}^{3}$-hybridized carbon atoms. Therefore, milling of SFG seems to decrease the crystallite size $(D / G$ ratio increasing) and generates amorphous $\mathrm{sp}^{3}$ carbon atoms (band at $1200 \mathrm{~cm}^{-1}$ appearing), while in carbon black, the milling leads to only slight generation of amorphous $\mathrm{sp}^{3}$-hybridized carbon atoms (low band at $1200 \mathrm{~cm}^{-1}$ ) and increases the disorder/number of defects $(D / G$ ratio not changing much, but bands gets broader and weaker).

Next, the electronic conductivities (Fig. 4) of the composites $\mathrm{SFG} / \mathrm{LiCoO}_{2}$, Ket $/ \mathrm{LiCoO}_{2}$ and $\mathrm{LiCoO}_{2}$ were measured by fourpoint probe method. We found out two main results from this measurement. One is that the electronic conductivities of both composites decrease upon ball-milling. Second is that the composite of $\mathrm{Ket} / \mathrm{LiCoO}_{2}$ has a lower electronic conductivity than the one of $\mathrm{SFG} / \mathrm{LiCoO}_{2}$. This result supports the data of electrochemistry (Fig. 1 and 2(a)) and Raman spectrum (Fig. 3); higher electronic conductivities come from higher intensities of ordered $G$ band $\left(I_{1580}\right)$ than disordered $\mathrm{D}$ band $\left(\mathrm{I}_{1350}\right)$ of the composites prepared for 0 and 5 min ball-milling. In the end, the composite having higher electronic conductivity provides superior electrochemical properties shown in Fig. 1 and 2(a). Increasing the ball-milling time provides more defect structure in both SFG and Ket. As the intensity of ordered $\mathrm{G}$ band $\left(\mathrm{I}_{1580}\right)$ indicates that SFG has a higher intensity than Ket in Raman spectrum shown in Fig. 3, the pristine structure of SFG is more ordered than the one of Ket. This Raman data supports the higher electronic conductivity of SFG/ $\mathrm{LiCoO}_{2}$ composite than the one of $\mathrm{Ket} / \mathrm{LiCoO}_{2}$ before and after $5 \mathrm{~min}$ of ball-milling shown in Fig. 4. However, the longer the ball-milling, the more disordered is the structure in carbon and the less electronically conductive is the composite.

The electronic conductivity of initial $\mathrm{LiCoO}_{2}$ without ball-milling and carbon was measured by 4-point probe method to be $3 \times 10^{-3}$ $\mathrm{S} / \mathrm{m}$. After ball-milling for 5,30 and $60 \mathrm{~min}$, the electronic conductivities of $\mathrm{LiCoO}_{2}$ without carbon were $2 \times 10^{-3}, 6 \times 10^{-3}$ and $5 \times 10^{-3} \mathrm{~S} / \mathrm{m}$, respectively. Thus, the electronic conductivity of $\mathrm{LiCoO}_{2}$ did not change significantly upon ball-milling compared to the composites.

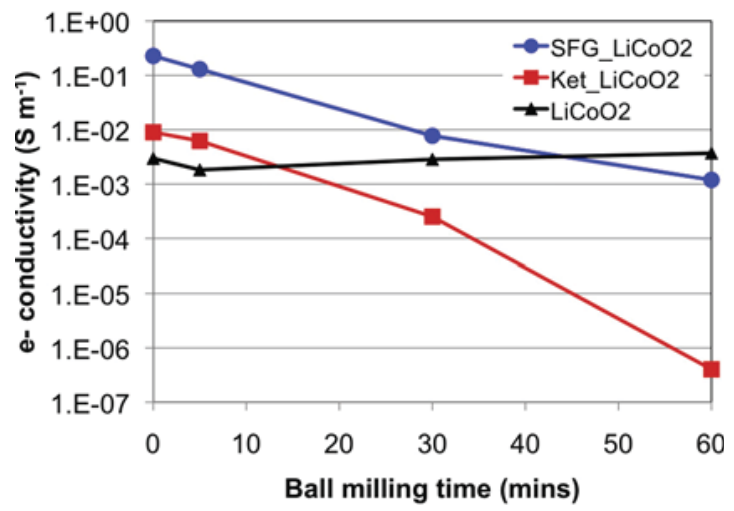

Fig. 4. The electronic conductivities of the composites, $\mathrm{SFG} / \mathrm{LiCoO}_{2}, \mathrm{Ket} / \mathrm{LiCoO}_{2}$ and $\mathrm{LiCOO}_{2}$ without carbon versus ball-milling time. 

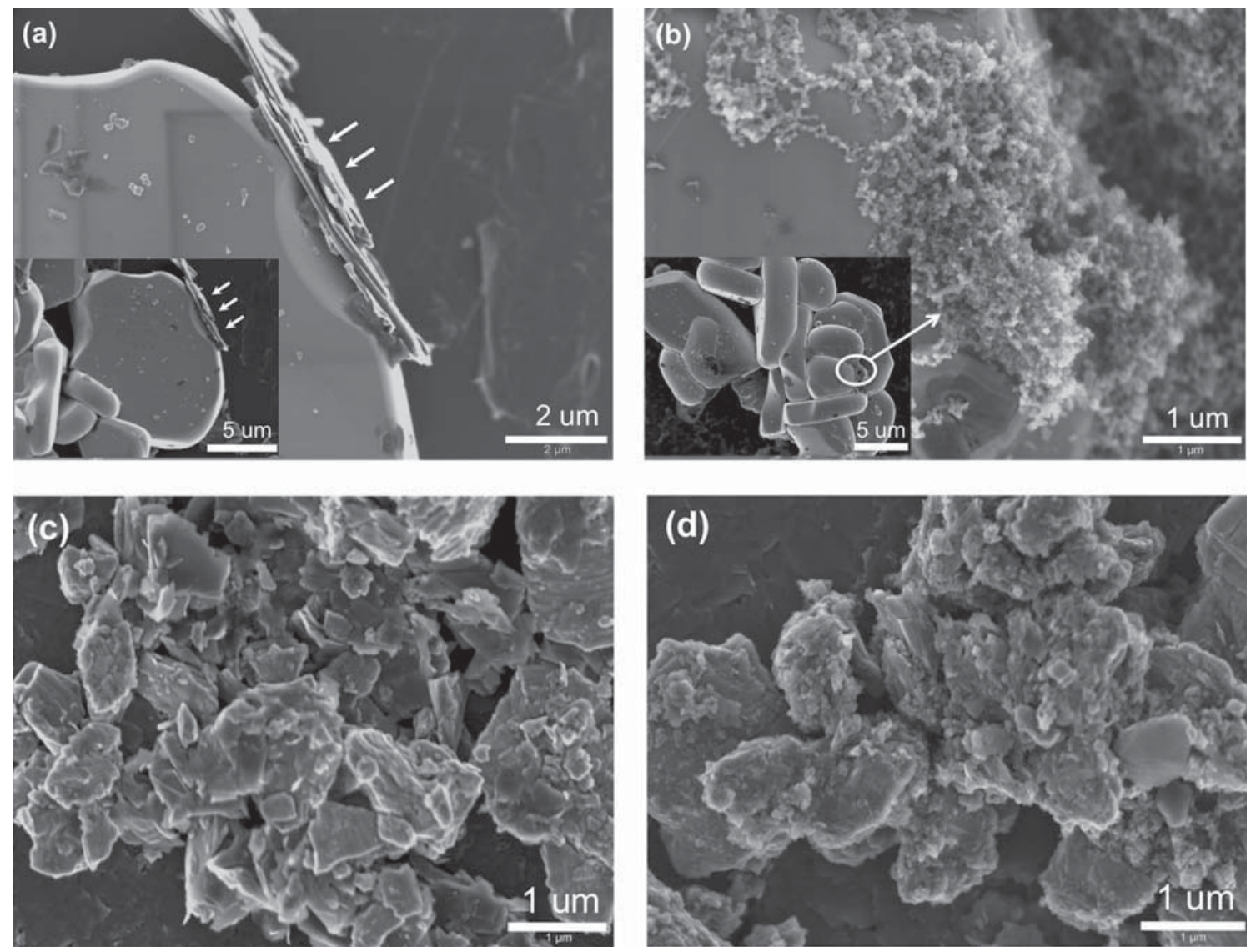

Fig. 5. The images of scanning electron microscopy of the composite materials: (a) and (c) SFG/LiCoO $\mathrm{L}_{2}$ prepared by ball-milling for 0 and 5 min, respectively and (b) and (d) $\mathrm{Ket} / \mathrm{LiCoO}_{2}$ prepared by ball-milling for 0 and $5 \mathrm{~min}$, respectively.

Electrodes require to be electronically conductive to produce the electrical energy while the redox reaction involving transition metal occurs. A long ball-milling, which decreases the ordered structure of carbon, is less desired due to the decreasing of the electronic conductivity. However, ball-milling induces a better mixing of the composite and improves the intimate contact between carbon and the active material as our previous studies showed [22,23]. Therefore, we investigated the morphologies of those composites with electron microscopies, using SEM and TEM.

The initial shape and size of SFG/LiCoO 2 and $\mathrm{Ket} / \mathrm{LiCoO}_{2}$ before ball-milling can be easily differentiated by SEM (Fig. 5 (a) and (b)). The particles of Ket (Fig. 5(b)) are rather agglomerated at the corners of large $\mathrm{LiCoO}_{2}$ particles. After ball-milling of the composite, it is homogeneously mixed and the shapes of $\mathrm{LiCoO}_{2}$ and carbon particles became irregular and large $\mathrm{LiCoO}_{2}$ particles are broken down to smaller sizes (Fig. 5 (c) and (d)). Thus, the ball-milling process broke the micron-sized large particles of $\mathrm{LiCoO}_{2}$ and SFG.

The difference of short and long ball-milling of $\mathrm{LiCoO}_{2}$ without carbon was verified by SEM (Fig. S1). A longer ball-milling of 30 and 60 min creates the secondary agglomerations (> $10 \mu \mathrm{m}$ ) of particles, likely due to local heating (the inset image of Fig. S1 (c) and (d)) The $\mathrm{SSA}$ of $\mathrm{LiCoO}_{2}$ and the composites of SFG/LiCoO 2 and $\mathrm{Ket} / \mathrm{LiCoO}_{2}$ are discussed below. We have verified the phase of $\mathrm{LiCoO}_{2}$ before and after ball milling by XRD. There was no phase transformation of $\mathrm{LiCoO}_{2}$ and no extra impurities created by ball milling (Fig. S2).

To study in more detail the morphology of carbon and the surface of composite before and after ball-milling, TEM images of the composites were taken (Fig. 6). The 0 min ball-milled composites, Fig. 6 (a) has rather separated particles of carbon and $\mathrm{LiCoO}_{2}$. Fig. 6 (b) shows the surface of $\mathrm{LiCoO}_{2}$ which is partially coated with Ket. The interface between Ket and $\mathrm{LiCoO}_{2}$ particles in Fig. 6 (b) shows a significant difference from the homogeneously coated $\mathrm{LiCoO}_{2}$ particles in Fig. 6 (d). The 5 min ball-milled composites (Fig. 6 (c) and (d)) have a homogeneous distribution of carbon and $\mathrm{LiCoO}_{2}$ particles. The carbon materials of both SFG and Ket are attached on the particles of $\mathrm{LiCoO}_{2}$. Particularly, Fig. 6 (d) shows a homogeneously coated thin layer of carbon (grey in the image) on the surface of $\mathrm{LiCoO}_{2}$ (black in the image). The 5-min ball-milling provides thus a close and more homogenous contact of carbon with $\mathrm{LiCoO}_{2}$. However, a longer milling leads to a dense and thick layer of carbon on $\mathrm{LiCoO}_{2}$ particles, as shown in Fig. 6 (e) and (f). This carbon layer can prevent the diffusion of lithium ions. In addition, it provided a decrease of electronic conductivity by creating a defect structure of carbon. As a result, the electrochemical properties of the composites prepared for 30 and $60 \mathrm{~min}$ ball-milling were inferior to the ones of the composites at 5 min of ball-milling as shown in Fig. 2.

The electrodes for lithium ion batteries must be also ionically conductive to obtain the insertion/extraction reaction of lithium ions. We therefore investigated the diffusion of lithium ions in the composite electrodes. The lithium ion diffusion coefficients $\left(D_{\mathrm{Li}}\right)$ of the composite electrodes were determined by cyclic voltammograms at various scan rates with using the Randles-Sevcik equation described below: [19]

$\mathrm{Ip}=\left(2.69 \times 10^{5}\right) \mathrm{n}^{3 / 2} \mathrm{AD}_{\mathrm{Li}}^{1 / 2} \mathrm{Cv}^{1 / 2}$

where Ip is the peak current; $n$ is the number of transfer electrons; $A$ is the surface area of the electrode; $C$ is the concentration of reactants; and $\mathrm{v}$ is the scan rate. Fig. 7 shows one example of the cyclic voltammograms of $\mathrm{SFG} / \mathrm{LiCoO}_{2}$ composite prepared by ball-milling for 5 min at various scan rates in order to determine the anodic current peaks. Then, the graphs of the square root of the scan rate, $\mathrm{mV}$ 

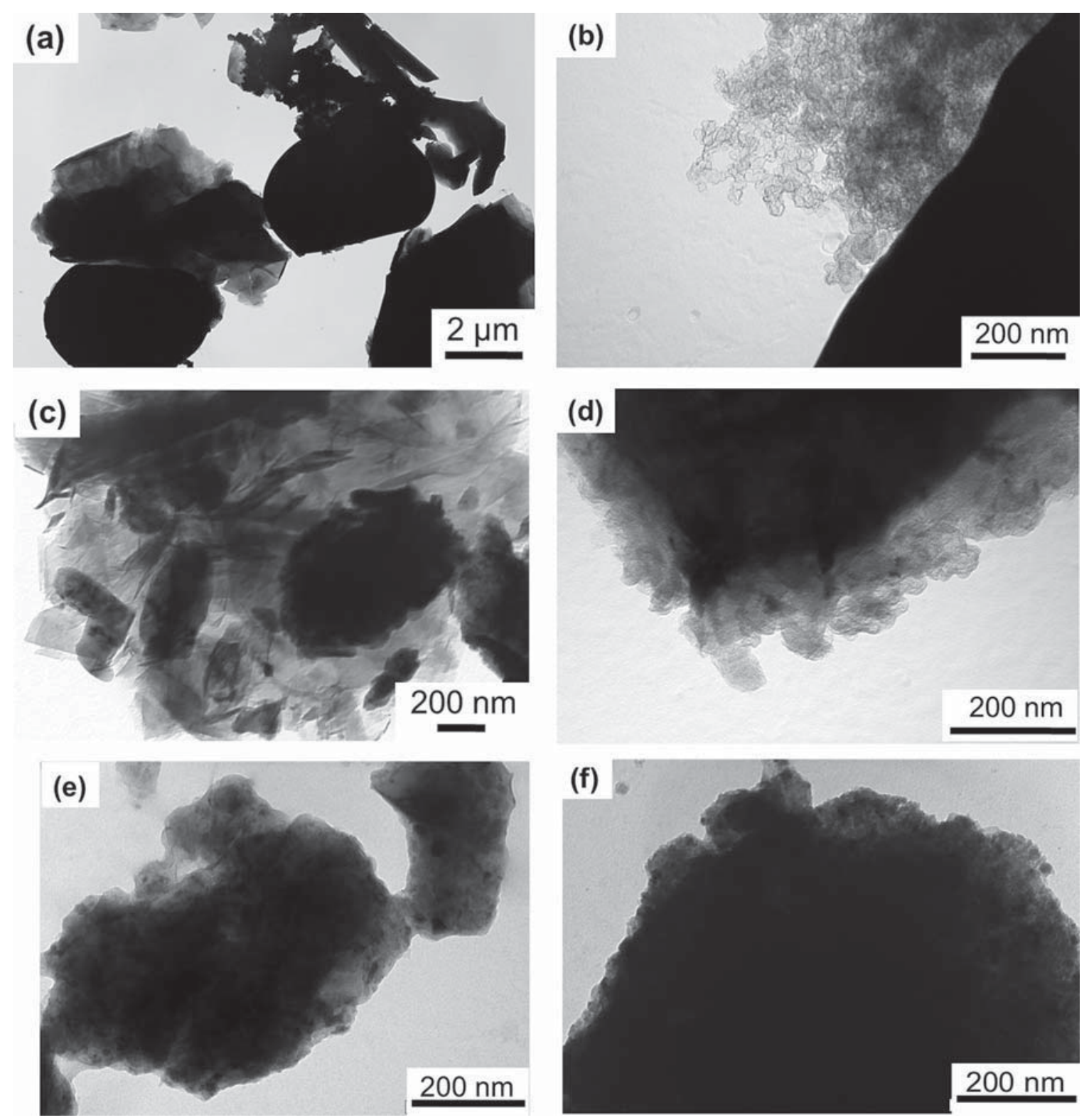

Fig. 6. The images of transmission electron microscopy of SFG/LiCoO 2 (left-hand side images) and Ket/LiCoO 2 (right-hand side images) composite prepared by ball-milled for $0 \mathrm{~min}$ (a) and (b), $5 \mathrm{~min}$ (c) and (d), and $60 \mathrm{~min}$ (e) and (f).

${ }^{1 / 2} S^{-1 / 2}$, versus the anodic peak give the slopes of each electrode, as shown in the inset of Fig. 7. These slopes represent the square root of the lithium ion diffusion coefficient value, $\mathrm{D}_{\mathrm{Li}}$.

Based on the calculation above, Fig. 8 shows the lithium ion diffusion coefficients of the composites' electrodes versus the time of ball-milling. The lithium ion diffusion coefficients decreased with the increase of ball-milling time in both composite materials of $\mathrm{SFG} / \mathrm{LiCoO}_{2}$ and $\mathrm{Ket} / \mathrm{LiCoO}_{2}$. The main reason of this may be related to the dense and thick layer of carbon on $\mathrm{LiCoO}_{2}$ prepared by ballmilling for 30 and $60 \mathrm{~min}$, which blocks the penetration of lithium ions into the particle of $\mathrm{LiCoO}_{2}$ as TEM images indicate in Fig. 6. On the other hand, the $5 \mathrm{~min}$ ball-milled SFG/LiCoO 2 composite provided highest $\mathrm{D}_{\mathrm{Li}}$ among all the composites. This is because the smaller particle size of $\mathrm{LiCoO}_{2}$ shortened the diffusion path length of lithium ions compared to the initial particle size of $\mathrm{LiCoO}_{2}$. This is confirmed by the measurement of the specific surface area (SSA) of $\mathrm{LiCoO}_{2}$, pristine and ball-milled for $5 \mathrm{~min}$. The SSAs of $\mathrm{LiCoO}_{2}$, the composites of $\mathrm{SFG} / \mathrm{LiCoO}_{2}$ and $\mathrm{Ket} / \mathrm{LiCoO}_{2}$ are shown in Fig. 9.
It revealed that the SSA of $\mathrm{LiCoO}_{2}$ increased from $0.52 \mathrm{~m}^{2} / \mathrm{g}$ (corresponding to a particle size of $2.28 \mu \mathrm{m}$ ) of the pristine material to $4.57 \mathrm{~m}^{2} / \mathrm{g}$ (corresponding to a particle size of $0.26 \mu \mathrm{m}$ ) after $5 \mathrm{~min}$ ball-milling. Further ball-milling ( $30 \mathrm{~min}$ ) still increased the SSA of $\mathrm{LiCOO}_{2}$, thus leading to yet smaller particle size of $\mathrm{LiCoO}_{2}$. However, 30 and $60 \mathrm{~min}$ of ball-milling produced also more agglomerated particles of $<10 \mu \mathrm{m}$ as shown in the insert of Fig. 6 (c) and (d). Therefore, the electrochemical properties of longer ball-milled composite electrodes were inferior to the shorter milling because of the dense carbon layer and the decreased the ionic conductivity of the composite.

According to Fick's law, ion transport is governed by the distance; $\tau=L^{2} / D$, where $D$ is the ion diffusion coefficient (the diffusivity), $\mathrm{L}$ is the distance of diffusion length, and $\tau$ is the time for the lithium ions needed for the diffusion distance. Thus, it is clear that the smaller particle sized $\mathrm{LiCoO}_{2}$ has the shorter diffusion length for lithium ions compared to the larger particles of $\mathrm{LiCoO}_{2}$ within a composite electrode. The $\mathrm{D}_{\mathrm{Li}}$ of other $\mathrm{LiCoO}_{2}$-carbon composite 


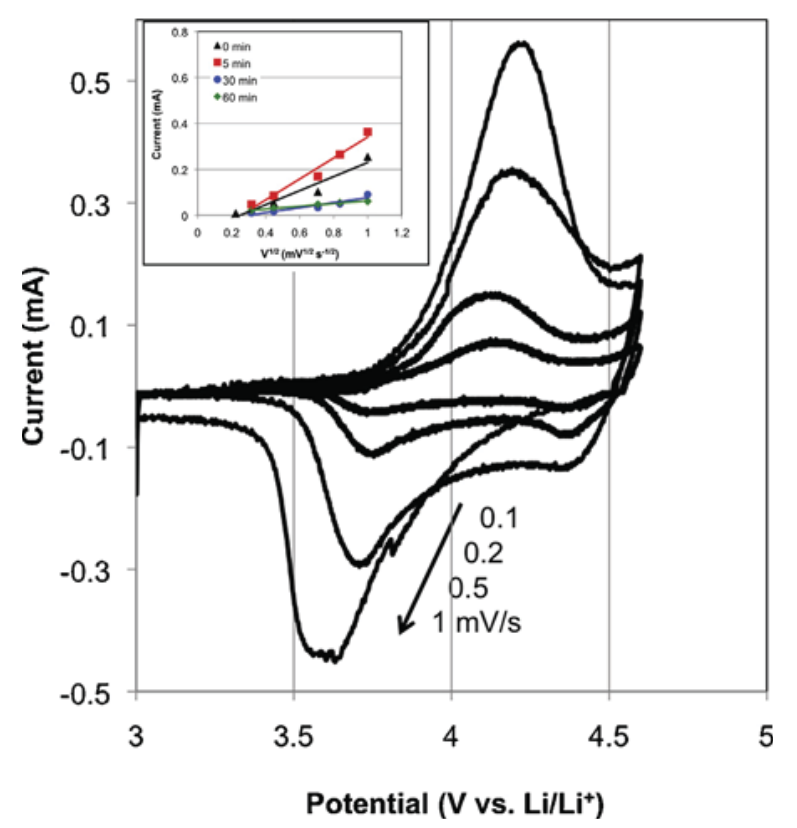

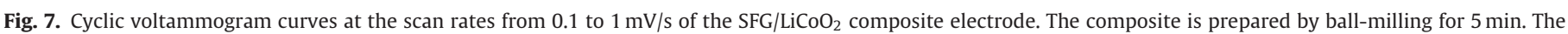
inset figure: The relationship between the anodic peak currents and the square root of the scan rate of SFG/LiCoO 2 with various ball-milling time of the composite.

electrodes is reported between $10^{-13}$ to $10^{-7} \mathrm{~cm}^{2} \mathrm{~S}^{-1}[24-29]$. The large difference of $\mathrm{D}_{\mathrm{Li}}$ is due to the different formula used for determining the diffusion coefficients by different techniques applied.

In summary, we showed that the characteristics of the composite and the structure of carbon were changed via ball-milling.

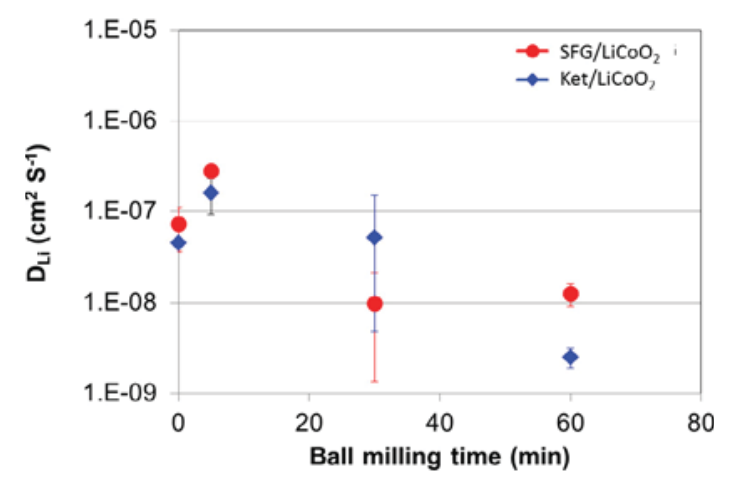

Fig. 8. The diffusion coefficients of lithium ion in $\mathrm{LiCoO}_{2}$ with SFG or Ketdecrease with increasing the time of ball-milling.

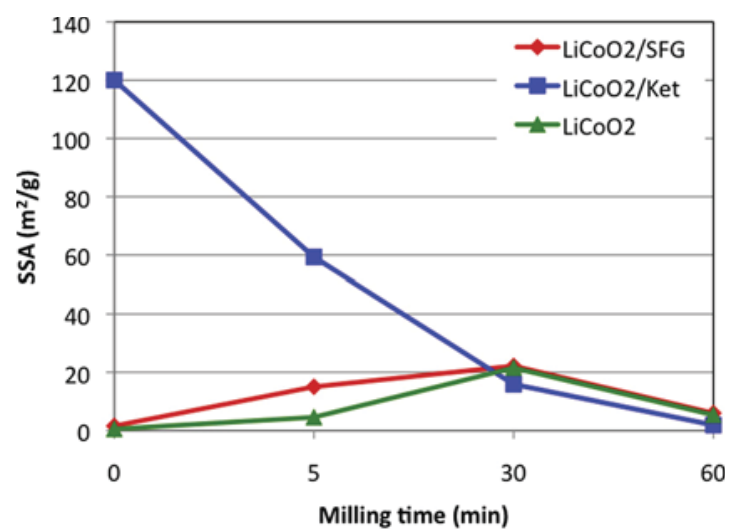

Fig. 9. SSAs of the composites, $\mathrm{SFG} / \mathrm{LiCoO}_{2}$ and $\mathrm{Ket} / \mathrm{LiCoO}_{2}$ and $\mathrm{LiCoO}_{2}$ prepared by ball-milling for various time.
Those characteristics affect the electrochemical properties of the electrodes. A short ball-milling improved the electrochemical properties based on the shorter diffusion path length of lithium ions by breaking large particles, on the homogeneous carbon coating and on the intimate mixing, while at the same time keeping high electronic conductivity. However, a long milling time increases the defect structure of carbon, decreases the electronic conductivity of composite, leads to a thick carbon layer in the composite and degrades thus the electrochemical properties.

\section{Conclusions}

The electronic and ionic conductivities of the cathode depend on the morphology of the composite influenced by the preparation method and the initial characteristics of carbon. We applied a ballmilling to prepare composites of different carbon sources and the active material $\mathrm{LiCoO}_{2}$. The ball- milling changes the characteristics of the composite as follows; i) a short ball-milling ( $5 \mathrm{~min}$ ) improved the homogeneity of the composite and provides intimate contact of carbon and $\mathrm{LiCoO}_{2}$, while a long ball-milling leads to a thick and dense carbon layer on $\mathrm{LiCoO}_{2}$ particles; ii) the ionic conductivity improved after a short ball-milling time due to the smaller particle size of $\mathrm{LiCoO}_{2}$ and improved the electrochemical properties, as shown by the lithium ion diffusion coefficient; iii) the disordered structure of SFG and Ket increased upon ball-milling, as observed by Raman spectroscopy; and iv) a long time of ball-milling ( 30 and $60 \mathrm{~min}$ ) decreased the electronic conductivity of the formed composite, Therefore, the electrochemical properties of the cathode are affected by the characteristics of cathode composite related with the transport of electrons and ions.

\section{Acknowledgement}

This study was supported by the Swiss National Science Foundation (National Research Program 64), EKZ (Elektrizitätswerke des Kantons Zürich), the FriMat (the Fribourg Center for Nanomaterials) and the University of Fribourg. The authors thank Timcal (Belgium) and Akzo Nobel (Germany) for kindly providing carbon materials. 


\section{Appendix A. Supplementary data}

Supplementary data associated with this article can be found, in the online version,

\section{References}

[1] S. Luo, K. Wang, J. Wang, K. Jiang, Q. Li, S. Fan, Adv. Mater. 24 (2012) 2294-2298.

[2] X. Li, F. Cheng, B. Guo, J. Chen, J. Phys. Chem. B 109 (2005) 14017-14024.

[3] F. Jiao, a.K.M. Shaju, P.G. Bruce, Angew. Chem. Int. Ed 44 (2005) 6550-6553.

[4] Y.S. Jung, P. Lu, A.S. Cavanagh, C. Ban, G.-H. Kim, S.-H. Lee, S.M. George, S.J. Harris, A.C. Dillon, Adv. Energy Mater. 3 (2013) 213-219.

[5] T. Wei, R. Zeng, Y. Sun, Y. Huang, K. Huang, Chem. Commun (2014).

[6] M.M. Thackeray, Prog Solid State Chem. 25 (1997) 1-71.

[7] S. Jouanneau, K.W. Eberman, L.J. Krause, J.R. Dahn, J. Electrochem. Soc. 150 (2003) A1637-A1642.

[8] T. Ohzuku, Y. Makimura, Chem. Lett (2001) 744-745.

[9] A.K. Padhi, K.S. Nanjundaswamy, J.B. Goodenough, J. Electrochem. Soc. 144 (1997) 1188-1194.

[10] C. Delacourt, L. Laffont, R. Bouchet, C. Wurm, J.B. Leriche, M. Morcrette, J.M. Tarascon, C. Masquelier, J. Electrochem. Soc. 152 (2005) A913-A921.

[11] M.M. Doeff, J.D. Wilcox, R. Yu, A. Aumentado, M. Marcinek, R. Kostecki, J. Solid State Electrochem 12 (2008) 995-1001.

[12] L. Dai, D.W. Chang, J.-B. Baek, W. Lu, Small 8 (2012) 1130-1166.
[13] M.E. Spahr, D. Goers, A. Leone, S. Stallone, E. Grivei, J. Power Sources 196 (2011) 3404-3413.

[14] J.-M. Chen, C.-H. Hsu, Y.-R. Lin, M.-H. Hsiao, G.T.-K. Fey, J. Power Sources 184 (2008) 498-502.

[15] K. Zaghib, J. Shim, A. Guerfi, P. Charest, K.A. Striebel, Electrochem. Solid-State Lett. 8 (2005) A207-A210.

16] Z. Bakenov, I. Taniguchi, J. Power Sources 195 (2010) 7445-7451.

17] Y. Uno, K. Tachimori, T. Tsujikawa, T. Hirai, ECS Transactions 25 (2010) 121-125.

[18] N.H. Kwon, Solid State Sci. 21 (2013) 59-65.

[19] A.J. Bard, L.R. Faulkner, Electrochemical methods: Fundamentals and Applications, John Wiley \& Sons, INC, New York, 2001.

[20] K. Kinoshita, Chemical and surface properties, John Wiley \& Sons, Inc, United States of America, 1988

[21] M.A. Pimenta, G. Dresselhaus, M.S. Dresselhaus, L.G. Canado, A. Jorio, R. Saito, Phys. Chem. Chem. Phys 9 (2007).

22] N.-H. Kwon, K.M. Fromm, Electrochim. Acta 69 (2012) 38-44.

[23] N.-H. Kwon, T. Drezen, I. Exnar, I. Teerlinck, M. Isono, M. Graetzel, Elecrochem Solid State Lett. 9 (2006) A277-A280.

[24] L. Sebastian, J. Gopalakrishnan, J. Mate. Chem. 13 (2003) 433-441.

[25] K. Dokko, M. Mohamedi, Y. Fujita, T. Itoh, M. Nishizawa, M. Umeda, I. Uchida, J. Electrochem. Soc. 148 (2001) A422-A426.

$26]$ Y.H. Rho, K. Kanamura, J. Electrochem. Soc. 159 (2004) A1406-A1411.

[27] Y.-I. Jang, B.J. Neudecker, N.J. Dudney, Electrochem. Solid-State Lett. 4 (2001) A74-A77.

[28] H. Xia, L. Lu, G. Ceder, J. Power Sources 159 (2006) 1422-1427.

[29] J. Xie, N. Imanishi, T. Matsumura, A. Hirano, Y. Takeda, O. Yamamoto, Solid State Ionics 179 (2008) 362-370. 